\title{
Modes of lubrication in human hip joints
}

\author{
B ARBARA J. ROBERTS,$^{1}$ A. UNSWORTH,$^{1}$ AND N. MIAN ${ }^{2}$ \\ From the ${ }^{1}$ Bioengineering Laboratory, Department of Engineering Science, and the ${ }^{2}$ Glycoprotein Research \\ Unit, University of Durham
}

SUMMARY Cadaveric hip joints were tested in a hip function simulator which subjected the femoral head to a cycle of loading and oscillation similar to that experienced during walking and measured the frictional torque transmitted to the acetabulum. Silicone fluids with viscosities from $10^{-2} \mathrm{~Pa} \mathrm{~s}$ (pascal second) to $30 \mathrm{~Pa} s$ were used as lubricants and the transition from mixed to full fluid film lubrication was observed around $5 \times 10^{-2} \mathrm{~Pa}$ s. Sodium carboxymethylcellulose solutions were also tested at the lower viscosities. Hyaluronidase digestion of samples of synovial fluid caused a significant increase in friction over the control samples. Trypsin digestion had no significant effect. No correlation between compliance of the cartilage and the frictional values was observed.

One of the factors which may contribute to the degeneration of the cartilage surfaces of human joints is a breakdown of the natural lubrication mechanism. It is important therefore to attempt to understand the way in which synovial fluid acts as a lubricant and what factors may cause the fluid to lose this ability. In this respect conflicting evidence has been published. $^{12}$

Swann et al. ${ }^{1}$ showed that the frictional resistance in a joint was not dependent on viscosity but seemed to depend on the presence of a protein in the synovial fluid. Their tests, however, used dogs' ankles in an arthrotripsometer, which applied a constant heavy load with an oscillating motion. These are conditions which predispose to boundary lubrication where a surface layer of protein may reduce friction, but they do not adequately represent the operating conditions of most joints.

O'Kelly et $a .^{2}{ }^{2}$ used human hip joints in both a pendulum and a joint function simulator. Their pendulum work indicated a mixed lubrication regimen unaffected by trypsin digestion, but the coefficient of friction was increased by hyaluronidase digestion. With the simulator the squeeze film action combined with the elasticity of the cartilage surfaces seemed to give full fluid film lubrication. O'Kelly et al.'s results with enzymatically digested fluid did not indicate the extent to which the digestion had been effective.

The present work was planned to extend that of O'Kelly et al. by testing several natural joints in a

Accepted for publication 2 June 1981.

Correspondence to Dr A. Unsworth, Department of Engineering Science, University of Durham, Science Laboratories, South Road, Durham DH1 3LE. simulator using synovial fluid digested with hyaluronidase or trypsin. One of the problems encountered with the use of synovial fluid is that only pathological fluid is available in sufficient quantities for adequate testing (including controls). This has a lower viscosity than fluid found in a healthy joint. Hence fluids could be used only within a limited viscosity range. This makes interpretation of results in terms of lubrication mechanisms difficult, and so tests were also performed with synthetic lubricants and synovial fluid with hyaluronic acid added to enhance its viscosity.

\section{Materials and methods}

\section{HIP FUNCTION SIMULATOR}

The joints were tested in a hip function simulator similar to the one which has been fully described elsewhere ${ }^{3}$ but with some additional features. Briefly it consisted of a hydraulic mechanism to apply dynamic loading to the joint while subjecting the joint to an oscillating motion representing flexion and extension. The angle of swing and the speed of oscillation could both be varied.

The acetabulum rested in a carriage suspended in 2 . hydrostatic bearings which had a very low coefficient of friction (around $10^{-4}$ ). As the femoral component oscillated, the frictional torque produced tried to rotate the acetabulum, which was restrained by a piezoelectric transducer. The output from this transducer was amplified and calibrated to give a continuous trace of torque. A strain-gauged load cell also gave a continuous trace of the applied load cycle. A potentiometer attached to the rotating shaft recorded 
Table 1 Human joints tested

\begin{tabular}{ll}
\hline Number of joints: & 9 \\
Age range: & $54-79$ years, mean 66 years \\
Sex: & 7 males, 2 females \\
Diameter of head: & $\begin{array}{l}41-54 \text { mm, mean } 48 \mathrm{~mm} \\
\text { Lubricants used: }\end{array}$ \\
& $\begin{array}{l}\text { silicone fluid-2 joints } \\
\text { sodium carboxymethylcellulose-3 joints } \\
\text { synovial fluid-8 joints }\end{array}$ \\
\hline
\end{tabular}

the oscillating displacement; this was useful in correlating sliding speed with load and frictional torque through the cycle.

A separate centralising jig was used to align the joint components in their holders. It was possible to centralise the specimens to within $0.05 \mathrm{~mm}$ at rightangles to the axis of rotation. Any misalignment along the axis of rotation was taken up by the axial play in the hydrostatic bearings. The bearings assembly could slide in a direction at right angles to the axis, so providing a self-centring mechanism for the acetabulum in relation to the femoral head.

\section{LU B RICANTS}

Two ranges of synthetic lubricants were used: silicone fluids (DC200 with viscosities from 10 to $30000 \mathrm{cS}$ (centi-Stoke)) which were Newtonian in behaviour and solutions of sodium carboxymethylcellulose (SCMC) (BDH Chemicals, high viscosity), in water, which exhibited non-Newtonian properties. ${ }^{4}$
PREPARATION OF SYNOVIAL FLUID

Synovial fluid was aspirated from effusions in several knee joints, and centrifuged at $14000 \mathrm{~g}$ for 30 minutes at $4^{\circ} \mathrm{C}$, with an $8 \times 50 \mathrm{ml}$ rotor in an MSE High Speed 18 centrifuge to remove particulate matter. The clear supernatants were stored at $-20^{\circ} \mathrm{C}$ until required. The $\mathrm{pH}$ values of the fluids were between $\mathrm{pH} 7 \cdot 5$ and $\mathrm{pH} 8 \cdot 7$. Since preliminary experiments showed that hyaluronidase and trypsin had little activity at these $\mathrm{pH}$ values, all samples of synovial fluid were subjected to equilibrium dialysis with several changes of buffer made up of $0.00408 \mathrm{M} \mathrm{Na}$ 5-5 diethylbarbiturate and 0.0625 M HCL with $0.088 \mathrm{M} \mathrm{Na} \mathrm{Cl}, \mathrm{pH} \mathrm{7 \cdot 2}$. Although $\mathrm{pH} 7 \cdot 2$ is not the optimal $\mathrm{pH}$, the enzymatic digestion was carried out here in order to minimise any $\mathrm{pH}$ effect on the lubricating ability of the synovial fluid as has been reported by Linn and Radin. ${ }^{5}$

\section{HYALURONIDASE DIGESTION}

A solution of hyaluronidase (SIGMA Type VI-S from bovine testes, $15000 \mathrm{NF}$ (National Formulary of the USA) units $/ \mathrm{mg}$ ) in the same buffer as used for the dialysis, concentration $10000 \mathrm{NF}$ units $/ \mathrm{ml}$ was added to $3 \mathrm{ml}$ of the dialysed synovial fluid. The enzyme activity in the reaction mixture was usually $100 \mathrm{NF}$ units $/ \mathrm{ml}$. The mixture together with a control sample of fluid to which no enzyme had been added was incubated in a shaking water bath at $37^{\circ} \mathrm{C}$ for 1 or 18 hours.

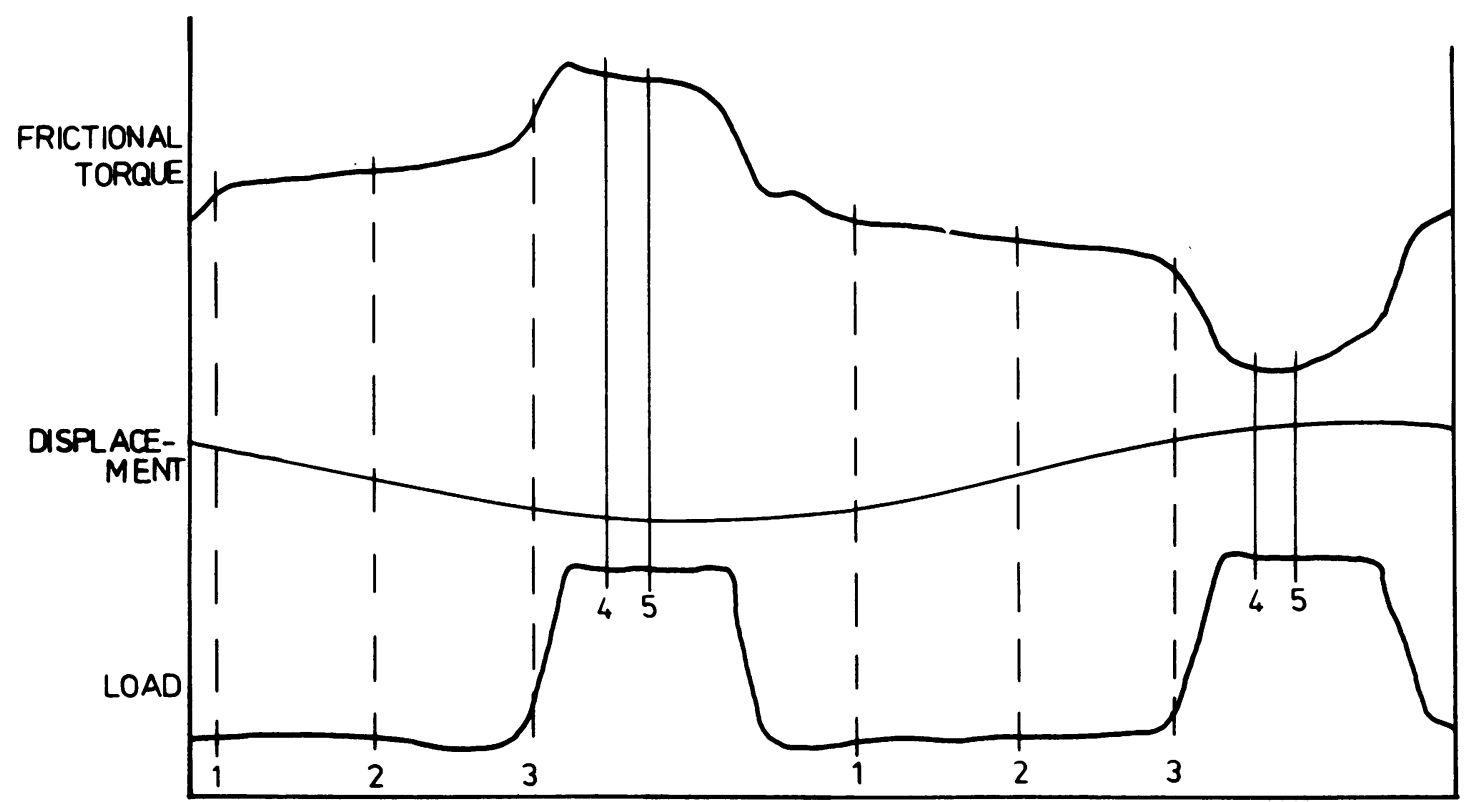

Fig. 1 Traces obtained from simulator showing positions at which measurements were taken. 


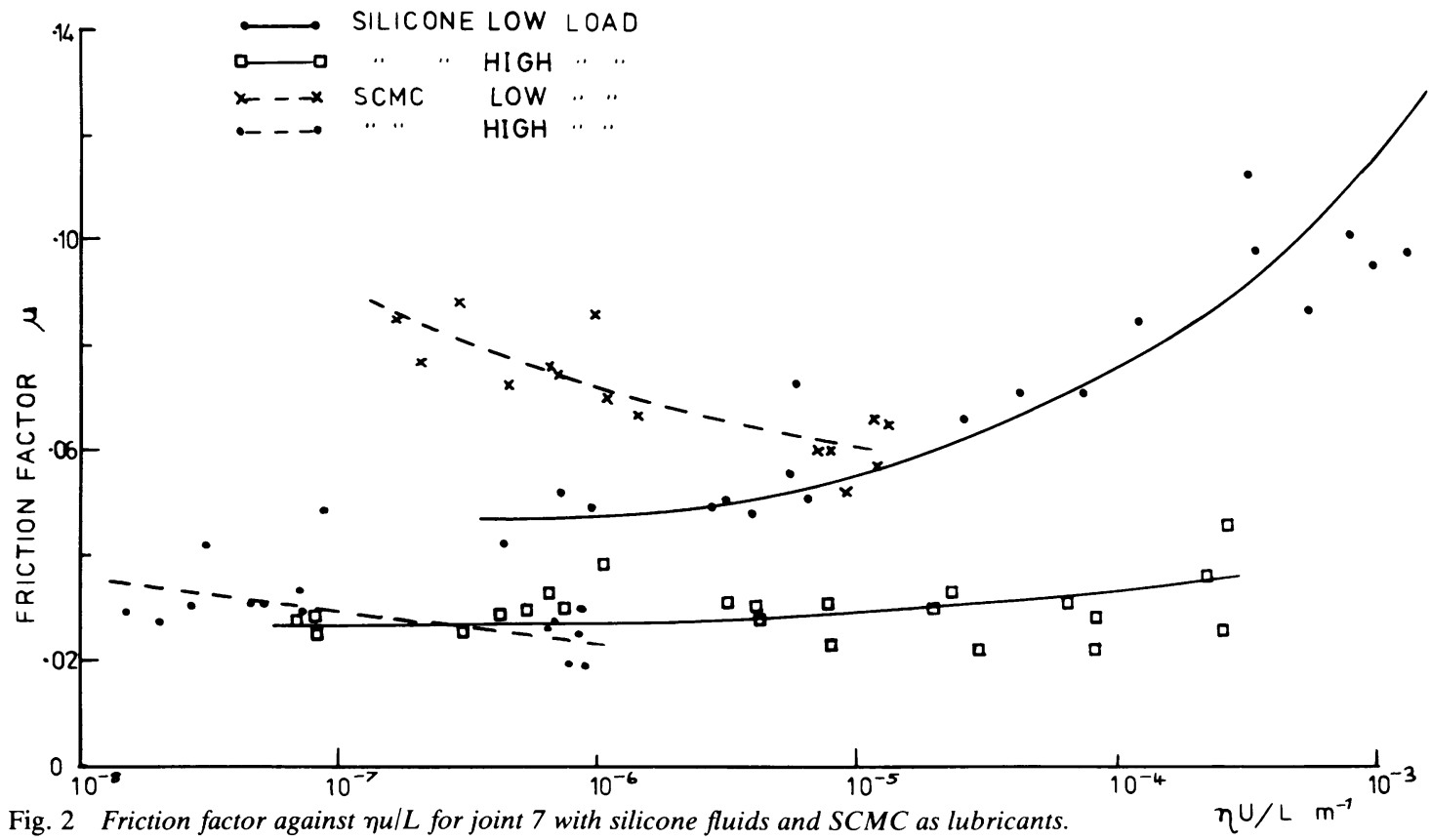

Since hyaluronidase splits $\beta-(1 \rightarrow 4)-N$ acetylglucosamine links in the hyaluronic acid, the new reducing $\mathrm{N}$-acetylglucosamine residues were measured as an index of the digestion of the hyaluronic acid in the synovial fluid. $E_{585}$ was measured in a Pye-Unicam SP18 000 spectrophotometer after treatment with p-dimethyl aminobenzaldehyde (DMAB) reagent following the method of Barrett. ${ }^{6}$

\section{TRYPSIN DIGESTION}

The synovial fluid was also digested with trypsin (SIGMA, type III 10000 benzoylarginine ethyl ester (BAEE) units/mg protein). The activity of trypsin in the reaction mixture was approximately 20000 units $/ \mathrm{ml}$. The mixture and control sample, to which no enzyme had been added, were incubated at $22^{\circ} \mathrm{C}$ for 1 or 18 hours.

Since Holmes et al. ${ }^{7}$ reported that antitrypsin activity is displayed by synovial fluid, preliminary experiments were carried out to ensure that the concentration of trypsin was sufficient to overcome this inhibitory effect. Measurement of the antitrypsin activity was carried out spectrophotometrically by the method of Burck ${ }^{8}$ with BAEE as a substrate. Digestion of the synovial fluid was then carried out with excess trypsin in the reaction mixture.

All the digested and control samples of synovial fluid were stored at $4^{\circ} \mathrm{C}$ and were used within a few hours.
VISCOSITY MEASUREMENTS

The viscosities of $1 \mathrm{ml}$ samples of the lubricants used were measured in a Ferranti-Shirley cone and plate viscometer at shear rates from $92 \mathrm{~s}^{-1}$ to $1290 \mathrm{~s}^{-1}$.

\section{FRICTION TESTS}

Nine human hip joints, detailed in Table 1, were obtained at necropsy from people with no history of joint disease and stored at $4^{\circ} \mathrm{C}$ before testing. Each joint was dissected and centrally mounted in holders using casting plaster. The cartilage surfaces were at all times kept moist with paper tissues soaked in Ringer's solution. The joints were then tested in the hip function simulator with the lubricants described above. $1 \mathrm{ml}$ of the lubricant sample was placed in the acetabulum, the femoral component was lowered into position, and traces of load and frictional torque obtained at each of 3 speeds of oscillation. The joint was then removed, wiped with tissue, soaked in Ringer's solution and wiped again before the next test.

\section{ELASTICITY TESTS}

When all the friction tests had been completed on a joint, samples of the cartilage were removed from the femoral head with a cylindrical punch, and compression tests were performed using an Instron universal testing machine. Cylindrical specimens of cartilage and underlying bone with a diameter of $5 \mathrm{~mm}$, were surrounded by Ringer's solution and compressed 
Table 2 Loads and sliding speeds for joint $54 \mathrm{~mm}$ in diameter

\begin{tabular}{llcc}
\hline Point & $\begin{array}{l}\text { Frequency of oscillation } \\
(\mathrm{Hz})\end{array}$ & $\begin{array}{l}\text { Load } \\
(\mathrm{N})\end{array}$ & $\begin{array}{l}\text { Sliding speed } \\
\mathrm{mm} \mathrm{s}^{-1}\end{array}$ \\
\hline 1 & 0.65 & 204 & 17.1 \\
1 & 0.83 & 204 & 21.9 \\
1 & 1.00 & 143 & 26.8 \\
2 & 0.65 & 239 & 24.3 \\
2 & 0.83 & 224 & 31.0 \\
2 & 1.00 & 367 & 37.9 \\
3 & 0.65 & 265 & 17.1 \\
3 & 0.83 & 245 & 21.9 \\
3 & 1.00 & 204 & 26.8 \\
4 & 0.65 & 1325 & 9.8 \\
4 & 0.83 & 1385 & 12.6 \\
4 & 1.00 & 1467 & 15.4 \\
5 & 0.65 & 1284 & 5.0 \\
5 & 0.83 & 1365 & 6.5 \\
5 & 1.00 & 1182 & 7.8 \\
\hline
\end{tabular}

between 2 impermeable platens at $0.3 \mathrm{~mm} \mathrm{~s}^{-1}$ up to a load of $80 \mathrm{~N}^{9}$ As the cartilage is very much softer than the bone, all the deformation was assumed to be in the cartilage.

\section{Results}

A friction factor ${ }^{10}$ defined as

$$
\mu=\frac{\text { Frictional torque }}{\text { Applied load } \times \text { radius of head }}
$$

was calculated at the 5 points through half a cycle, shown in Fig. 1. The values of frictional torque at a particular point for the 2 halves of the cycle were averaged. Since the loading cycle is almost symmetrical, this averaging eliminates errors in the magnitude of frictional torque caused by off-centre mounting of the joint. Table 2 gives typical loads and sliding speeds for the 5 points at $0.65,0.83$, and $1.0 \mathrm{~Hz}$ frequency of oscillation. Points 1,2 , and 3 are low loads, while points 4 and 5 are in the highly loaded region. The sliding speed varies sinusoidally with time, and point 2 was taken at the maximum speed. Points 1 and 3 are the same speed each side of the maximum and points 4 and 5 are slower speeds.

\section{SILICONE FLUID AS LUBRICANT}

Joints $\mathrm{H} 7$ and $\mathrm{H} 9$ were tested with a range of 8 silicone fluids (viscosities from $10^{-2} \mathrm{~Pa}$ s to $30 \mathrm{~Pa} \mathrm{~s}$ ). The results have been expressed in the form $\mu$ against $\eta \mathrm{u} / \mathrm{L}$, where $\eta$ is the viscosity of the lubricant, $\mathrm{u}$ the sliding speed, and $L$ the applied load, which is a useful method for demonstrating the lubrication mechanism operating. Fig. 2 shows the results for points 2 and 4 with joint $H 7$. For each curve $u$ and $L$ are essentially constant so the abscissa varies only with viscosity. The curves. obtained exhibit the rising characteristic above $\eta \mathrm{u} / \mathrm{L} \sim 10^{-5} \mathrm{~m}^{-1}$ typical of full fluid film lubrication. At high loads (point 4) the friction factor varies very little with viscosity, $\mu$ being between 0.02 and 0.04 .

SODIUM CARBOXYMETHYLCELLULOSE

Joints $\mathrm{H6}, \mathrm{H} 7$, and $\mathrm{H} 9$ were tested with a range of

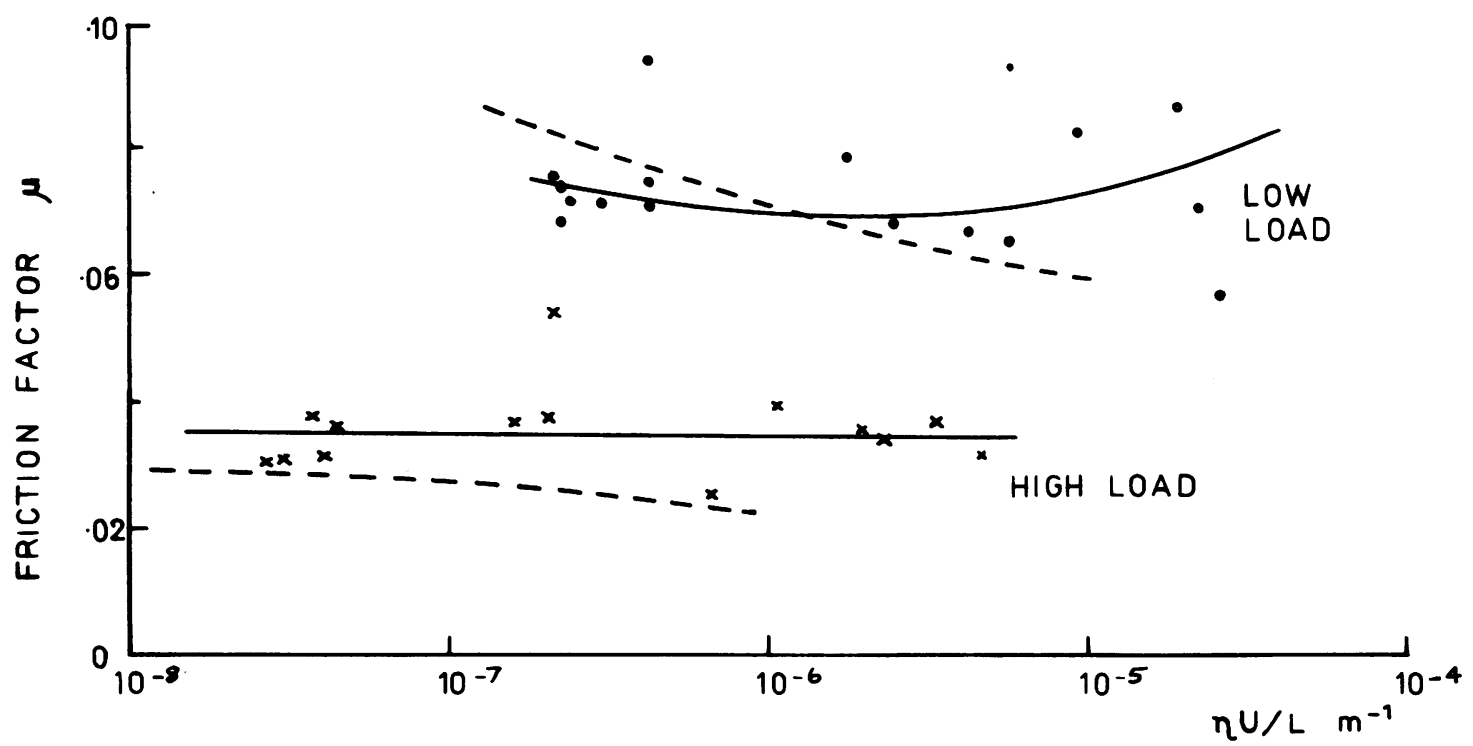

Fig. 3 Friction factor against $\eta$ u/L for joint 9 with synovial fluid and hyaluronic acid. Dotted line shows SCMC curve for comparison. 
Table 3 Treatment of synovial fluid with hyaluronidase for joint 8

\begin{tabular}{|c|c|c|c|c|c|c|}
\hline \multirow[t]{2}{*}{ Ref. } & \multirow{2}{*}{$\begin{array}{l}\text { Vol. synovial fluid } \\
\text { (ml) }\end{array}$} & \multirow{2}{*}{$\begin{array}{l}\text { Hyaluronidase } \\
\text { (units/ml) }\end{array}$} & \multicolumn{2}{|l|}{ Incubation } & \multirow{2}{*}{$\begin{array}{l}\text { Viscosity } \\
\left.\text { (cP at } 10^{2} s^{-1}\right)\end{array}$} & \multirow{2}{*}{$\begin{array}{l}\text { NAG released } \mu g / m l \\
\text { synovial fluid }\end{array}$} \\
\hline & & & Temp. $\left({ }^{\circ} \mathrm{C}\right)$ & Time (h) & & \\
\hline A8 & 3 & - & - & - & $7 \cdot 7$ & 2 \\
\hline B8 & 3 & - & 37 & 1 & 7.9 & 2 \\
\hline C8 & 3 & 100 & 37 & 1 & $2 \cdot 0$ & 61 \\
\hline E8 & 3 & - & 37 & 18 & $8 \cdot 3$ & 3 \\
\hline D8 & 3 & 100 & 37 & 18 & $2 \cdot 2$ & 140 \\
\hline
\end{tabular}

solutions of sodium carboxymethylcellulose (SCMC) in water. The viscosities of these fluids covered the lower part of the range of the silicone fluids when the shear dependence was taken into consideration, up to $0.13 \mathrm{~Pa}$ s at $1290 \mathrm{~s}^{-1}$. Fig. 2 shows typical curves for this lubricant compared with those for silicone fluid; the high load points lie on the same curve as silicone, the low load points were slightly higher and decreased with increasing viscosity.

\section{SYNOVIAL FLUID WITH HYALURONIC ACID}

AD D ED

One joint (H9) was tested with hyaluronic acid added to the synovial fluid in 3 different concentrations,
$2 \cdot 5,5$, and $10 \mathrm{mg} / \mathrm{ml}$, in order to increase its viscosity. Fig. 3 shows curves obtained for high and low loads. These are very similar in form to those obtained with SCMC but with a more pronounced minimum around $\eta \mathrm{u} / \mathrm{L}=3 \times 10^{-5} \mathrm{~m}^{-1}$ for the low loads, and a constant value of $\mu=0.033$ for high loads.

\section{SYNOVIAL FLUID DIGESTED WITH}

\section{HYALURONIDASE}

Six of the joints were tested with synovial fluid which had been digested with hyaluronidase and compared with the control fluids which had undergone the same procedure but without the addition of enzyme. Typical
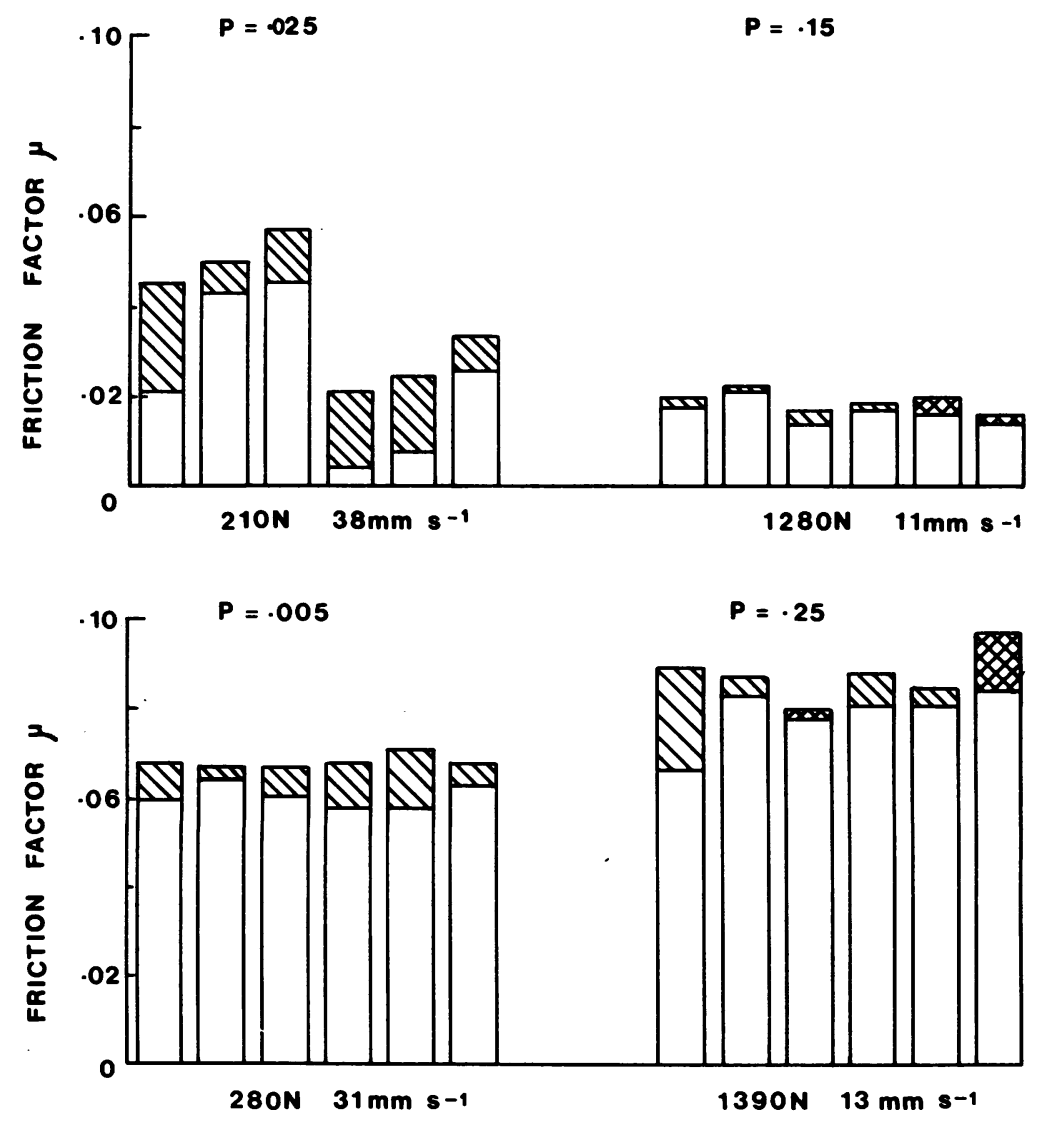

Fig. 4 Effect of hyaluronidase digestion on (a)joint 6 , (b) joint 8. Single hatching indicates increase in $\mu$ after digestion, cross hatching indicates decrease. 


\section{Roberts, Unsworth, Mian}

Table 4 Treatment of synovial fluid with trypsin for joint 8

\begin{tabular}{|c|c|c|c|c|c|}
\hline \multirow[t]{2}{*}{ Ref. } & \multirow{2}{*}{$\begin{array}{l}\text { Vol. synovial fluid } \\
\text { (ml) }\end{array}$} & \multirow[t]{2}{*}{ Trypsin (mg/ml) } & \multicolumn{2}{|l|}{ Incubation } & \multirow{2}{*}{$\begin{array}{l}\text { Viscosity } \\
-\left(c P \text { at } 10^{3} \mathrm{~s}^{-1}\right)\end{array}$} \\
\hline & & & $\operatorname{Temp} .\left({ }^{\circ} \mathrm{C}\right)$ & Time (h) & \\
\hline J8 & 3 & - & 22 & 1 & $9 \cdot 2$ \\
\hline L8 & 3 & 2 & 22 & 1 & $9 \cdot 0$ \\
\hline K8 & 3 & - & 22 & 18 & $9 \cdot 9$ \\
\hline M8 & 3 & 2 & 22 & 18 & $9 \cdot 1$ \\
\hline N8 & 3 & 2 & - & - & $9 \cdot 0$ \\
\hline
\end{tabular}

results for the reduction in viscosity obtained can be seen in Table 3 by comparing C8 with B8 and D8 with E8. A 4-fold decrease in viscosity was observed. Colorimetric determinations of the reducing terminal $\mathrm{N}$-acetylglucosamine (NAG) residues in enzymatically treated synovial fluid samples confirmed that the reduction in viscosity was due to the digestion of the hyaluronic acid. Histograms were used to show the results before and after digestion. Typical examples are shown in Fig. 4. Student's $t$ test was performed on the paired data for each joint and at low loads the difference was always significant $(p \leqslant 0 \quad 05)$. At high loads there was no significant difference in the 2 populations.

SYNOVIAL FLUID DIGESTED WITH TRYPSIN

Five joints were tested with synovial fluid digested with trypsin and compared with their respective control fluids. Table 4 shows that this digestion did not significantly affect the viscosity of the fluids (compare $\mathrm{J} 8$ with $\mathrm{L} 8$ and $\mathrm{K} 8$ with M8). The effect on the friction factor was found to be variable, sometimes

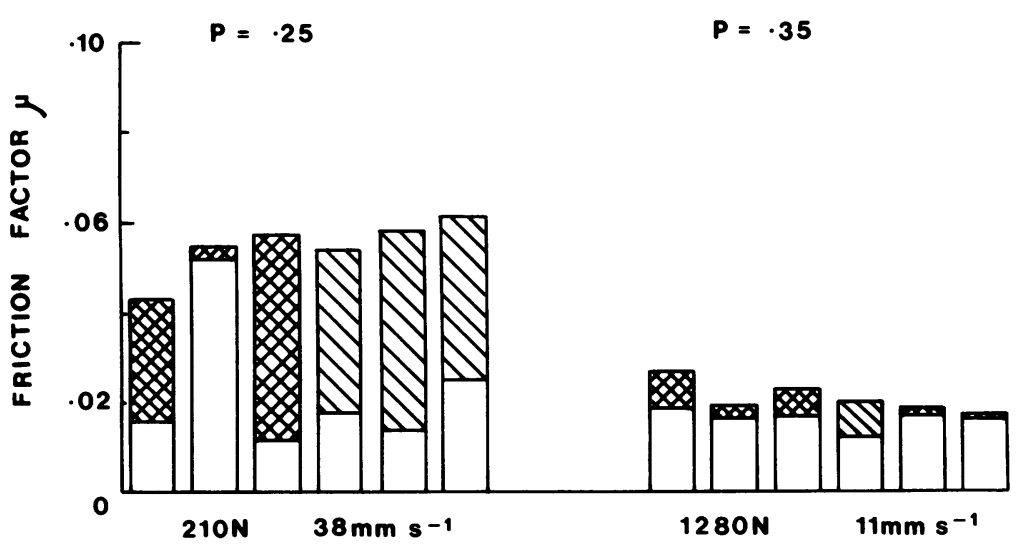

$P=\cdot 20$

$P=\cdot 10$

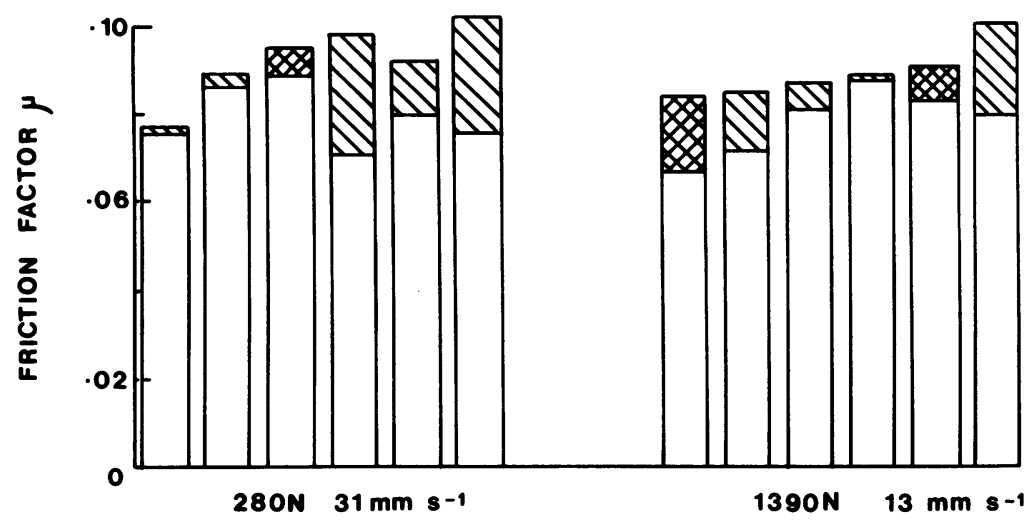

Fig. 5 Effect of trypsin digestion on (a) joint 6 (b) joint 8. Single hatching indicates increase in $\mu$ after digestion, cross hatching indicates decrease. 
Table 5 Cartilage thickness and compliance values compared with friction factors for Ringer's solution (except joint 7 , which is compared with SCMC friction factors)

\begin{tabular}{|c|c|c|c|c|}
\hline \multirow[t]{2}{*}{ Joint } & \multirow[t]{2}{*}{$t(\mathrm{~mm})$} & \multirow{2}{*}{$\begin{array}{l}\text { Compliance } \\
\times 10^{8}\left(\mathrm{~m}^{2} \mathrm{~N}^{-1}\right)\end{array}$} & \multicolumn{2}{|c|}{$\mu$ (Ringer's) } \\
\hline & & & Low load & High load \\
\hline 2 & 1.86 & $5 \cdot 9$ & $0 \cdot 2$ & 0.075 \\
\hline 3 & $2 \cdot 36$ & $9 \cdot 1$ & 0.0419 & 0.0323 \\
\hline 4 & $2 \cdot 32$ & $4 \cdot 6$ & 0.0644 & 0.0675 \\
\hline 5 & $2 \cdot 06$ & $5 \cdot 1$ & 0.0537 & 0.0591 \\
\hline 6 & 1.93 & $4 \cdot 5$ & 0.0376 & 0.017 \\
\hline 7 & 2.04 & $6 \cdot 0$ & $0.0611^{*}$ & $0.0220^{*}$ \\
\hline 8 & $2 \cdot 27$ & $5 \cdot 4$ & 0.083 & 0.087 \\
\hline
\end{tabular}

*SCMC.

increasing sometimes decreasing, and at other times showing negligible effect (Fig 5). Student's $t$ test for each joint showed that the differences were not significant.

\section{ELASTICITY TESTS}

From the compression tests on the cartilage a graph of stress (defined as load divided by original crosssectional area) against logarithmic strain, $\epsilon$ was plotted. The logarithmic strain is used since the strains involved are large and it is defined as

$\epsilon=-\int_{h_{0}}^{h} \frac{d h}{h}=\ln \left(\frac{h_{0}}{h}\right)=\ln \left(\frac{h_{0}}{h_{0}-d}\right)$

where $h_{0}$ is the initial thickness of cartilage, $h$ the thickness at any given time, and $d$ the decrease in thickness at that time. The inverse slope of the stress-strain curve at a stress of $3 \mathrm{MPa}$ (megapascals) gives a value for the 'compliance' of the material. ${ }^{9}$ No correlation was found between either the compliance or the initial thickness of the cartilage and the friction factor obtained with Ringer's solution as lubricant. A summary of the results at a speed of 0.83 $\mathrm{Hz}$ is given in Table 5 .

\section{Discussion}

\section{SYNTHETIC LUBRICANTS}

The results for silicone fluid at low loads clearly indicate that a fluid film mechanism is operating in the joint, with a transfer from mixed lubrication at very low viscosities to full fluid film for viscosities above 5 $\times 10^{-2} \mathrm{~Pa}$ s. At high loads, which occur suddenly in the walking cycle, there will be a substantial squeeze film effect in addition to the hydrodynamic mechanism. As the viscosity of the fluid increases, the squeeze film time will increase, and hence there will be a thicker film of lubricant separating the 2 surfaces than would be expected from a purely hydrodynamic effect. This could explain the results obtained where, at high loads, a constant value of $\mu$ is obtained for all viscosities. The increased load will also cause increased deformation of the cartilage, and hence a small film thickness may be required to separate the surface asperities and produce a full film of fluid.

The SCMC appears to behave in a similar manner at high loads, with a similar constant value for $\mu$. However, at low loads the SCMC operates in the mixed lubrication region with $\mu$ decreasing with increasing viscosity. This could simply be because the viscosities, at the relevant shear rates, were too low for full fluid film.

SYNOVIAL FLUID AS LUBRICANT

The results for synovial fluid with hyaluronic acid added to raise the viscosity are consistent with the results from synthetic lubricants. At high loads $\mu$ is once again constant, whereas at low loads the results encompass the minimum of the curve, that is, the transition from mixed to full fluid film which occurs at a viscosity of $0.025-0.1 \mathrm{~Pa} \mathrm{~s}$, a likely value for healthy synovial fluid.

One of the difficulties in using synovial fluid is that in order to obtain sufficient quantities for controlled tests it is only practicable to use degenerate human fluid. Healthy bovine fluid, obtainable in larger quantities, was not used, since its viscosity is even less than pathological human fluid.

Digestion with hyaluronidase cannot decrease the fluid's viscosity more than about 4-fold. Moreover, results with synovial fluid seem to display much greater fluctuations under the same conditions than the synthetic lubricants. At high loads the $t$ test on the results showed no difference in friction before and after digestion with either hyaluronidase or trypsin. This is consistent with all the other high load results in which $\mu$ remained constant. However, at low loads the hyaluronidase-digested fluid always showed a significant rise in $\mu$. This implies that the joint is operating in the mixed region, as would be expected by comparison of the viscosities with Fig. 3. It seems that at low loads the viscosity of the fluid and hence its hyaluronic acid content has a marked effect on its lubricating ability.

Results after trypsin digestion at low loads, although showing no significant difference, did show large variations in $\mu$.

\section{ELASTICITY TESTS}

The elasticity tests show no correlation with $\mu$, but this does not mean that the elasticity of cartilage is not important. The reasons for this could be related to the small range of cartilage compliance values used in these experiments and the low viscosity of Ringer's solution. Since these tests were investigating normal joint lubrication, the cartilage used was as near normal as could be obtained, and this resulted in 
a small range of compliance values. All the experiments were carried out with different synovial fluid samples, and hence to eliminate the effects of lubricant in these experiments the results obtained with Ringer's solution as lubricant had to be compared. However, in physiological situations the compliance could well be important to the squeeze film mode of lubrication.

\section{CONCLUSIONS}

It is useful to examine the friction factor of natural joints with synthetic lubricants, since it is easy to obtain a wide range of viscosities, and the results are then helpful in interpreting the synovial fluid results. This work shows that at low loads the viscosity of synovial fluid is important in reducing friction. At higher loads $\mu$ remains constant regardless of the viscosity, but the values are lower than at the lower loads. Hence at higher loads the squeeze film effect, which is accentuated by the dynamic loading, leads to full fluid film even with lubricants of very low viscosity.

We thank Mr A. Cross, FRCS, Sunderland District General Hospital, and Mr B. B. Porter, FRCS, Dryburn Hospital, Durham, for the provision of specimens, and Mr R. Mand for technical assistance. We also thank the Arthritis and Rheumatism Council for providing financial support.

\section{References}

1 Swann D A, Radin E L, Nazimiec M, Weisser P A, Curran N, Lewinnek G. Role of hyaluronic acid in joint lubrication. $A n n$ Rheum Dis 1974; 33: 318-26.

${ }^{2}$ O'Kelly J, Unsworth A, Hall D A, Wright V. A study of synovial fluid and its constituents in the friction and lubrication of hip joints. Engineering Med 1978; 7: 73-83.

3 O'Kelly J, Unsworth A, Dowson D, Jobbins B, Wright V. Pendulum and simulator for studies of friction in hip joints. In: Dowson D, Wright V, eds. Evaluation of Artificial Joints. Biological Engineering Society, 1977: 19-29.

${ }^{4}$ Cooke A F, Dowson D, Wright V. The rheology of synovial fluid and synthetic lubricants for degenerate synovial joints. Engineering Med 1978; 7: 66-72.

${ }^{5}$ Linn F C, Radin E L. Lubrication of animal joints. III. The effect of certain chemical alterations of the cartilage and lubricant. Arthritis Rheum 1968; 11: 674-82.

6 Barrett A J. In: Dingle J T, ed. Lysosomes, A Laboratory Handbook. Amsterdam: North Holland, 1972: 115.

${ }^{7}$ Holmes W F, Keefer C S, Myers W K. Anti-tryptic activity of synovial fluid in patients with various types of arthritis. $J$ Clin Invest 1935; 14: 124-30.

${ }^{8}$ Burck P J. In: Perlmann C E, Lorand L, eds. Methods in Enzymology XIX. London: Academic Press, 1970: 907.

- Gore D M. Mechanical properties of articular cartilage-variation with depth $\mathrm{PhD}$ Thesis. University of Durham, 1981.

${ }^{10}$ Unsworth A. The effects of lubrication in hip joint prostheses. Phys Med Biol 1978; 23: 253-68. 